\title{
SOIURI INOVATIVE LOCALE ȘI INTRODUSE DE CAIS
}

\author{
Pintea M. \\ Institutul Ştiințifico-Practic de Horticultură şi Tehnologii Alimentare. \\ Str. Costiujeni 14,Chişinău MD2019. Republica Moldova. \\ E-mail: mariapintea@yandex.ru
}

\begin{abstract}
In the article there are discussed some biological and agronomical features of new perspective varieties of apricot, created in RIHAT or introduced in the Republic of Moldova. Based on evaluated level of adaptabilitity and large ecological plasticity to variable pedo-climatic conditions of local culture variety Vasile Cociu and Codrean there are registered for industrial culture. Some introduced foreign varieties (Wondercot, Orange Red, Tsunamy, Big Red, Faralia, Farbaly,etc.) also there are proposed for limited tests in different pomological zone of country. Noticed genotypes are proposed also for utilization within future apricot breeding programs.
\end{abstract}

Key words: apricot, varieties, breeding, inovation, Rep. Moldova

\section{Introducere}

Răspîndirea relativ rapidă a culturii caisului din ultimii ani se datoreşte nu numai calităţilor nutritiţionale deosebite ale fructelor, dar, în primul rînd precocităţii de rodire, şi respectiv, prezenţei masive pe piaţa de fructe deja la sfîrşitul lunii iunie şi începutul lunii iulie. Imbunătăţirea continuă a sortimentului de cais în corespundere cu cerinţele noi faţă de fructe este o sarcină importantă, mai ales avînd în vedere schimbările de climă, apariţia pieţelor noi din țările vecine. Astăzi sunt cerute soiuri cu caracteristici deosebite ale fructelor, dar şi pomi pretabili la densităţi mari de plantare, precum şi pentru mecanizarea majorităţii lucrărilor de întreţinere; sistem radicular al portaltoiului adaptabil la diferite tipuri de soluri, în special din cele "grele", specifice pentru multe teritorii destinate caisului în cazul republicii Moldova; repaus profund al mugurilor florifer; rezistenţă genetică la ger, fluctuaţii de temperaturi stresante din timpul iernii şi primăverii; potenţial fiziologic de echilibrare a creşterii şi fructificării, adică cu adaptabilitate bună şi plasticitate ecologică largă $(2,4,6,7)$. Fructele, la rîndul lor, trebuie să fie mari, foarte atractiv colorate, cu pulpa fermă dar suculentă, textura fină, gust echilibrat şi aromă specifică de cais, cu sîmbure cît mai mic, detaşabil de la pulpă.

\section{Materiale şi metode}

Investigaţile experimentale au fost efectuate în colecţiile naţionale de cais (Staţiunea Experimentală „Codrul”, Institutul Ştiinţifico-Practic de Horticultură şi Tehnologii Alimentare (IŞPHTA), la Staţiunea Comisiei de Stat pentru Testarea Soiurlor de Plante Pomicole Tvardiţa), precum și la producătorii localide caise din toate zonele pomicole ale țării. În calitate de material biologic s-au utilizat peste 290 soiuri şi selecţii evidenţiate (inclusiv din colecţiile de hibrizii obţinuţi prin cultura in vitro a embrionilor imaturi).Ca portaltoi a fost folosit biotipul de zarzăr MVA (rezistent la geruri de iarnă şi îngheţuri de primăvară), scheme 
de bază de plantare: 5 x 2 m, 5 x 3m şi 5 x 4m. Cercetările s-au îndeplinit conform principiilor metodologice şi metodelor aprobate în ameliorarea şi studiul speciilor pomicole $(2,5)$.

\section{Rezultate şi discuții}

Caisul este o cultură tradișională în Republica Moldova. În ultimii ani atît în Republica Moldova, cît şi pe plan internaţional suprafețele industriale de plantaţii de cais s-au mărit.De notat că în majoritatea ţărilor cultivatoare caisul constituie o sursă importantă de venituri, deoarece cerinţa în caise proaspete și procesate ( mai ales deshidratate) pe piaţa de fructe este dintotdeauna peste tot nelimitată. În ultimul timp sunt mult promovate soiurile cît mai timpurii (dar și foarte tardive), cu aspect foarte atractiv (în primul rînd pielița elastică,roșie pe aproape toată suprafața fructului, fermitatea pulpei suculente, etc.). În țara noastră se încearcă deja pe suprafețe mici experimentale o serie întreagă de asemenea soiuri inovative (cum ar fi: Kyoto, Lady Cot, Pinkot, Pricia, Farlis, Alice Col, Anegat, Digat, Gilgat, Iziagat, Jengat), clarificînd transportabilitatea fructelor, toleranța la PPV și sustenabilitatea productivităţii.

Varierea producţiilor de caise de la an la an este legată de un şir de 'probleme' ale lui, care provoacă în ţară iregularităţi de fructificare.Ele pot şi trebuie să fie depăşite prin măsuri agrotehnice/ecologice principiale. Printre ele notăm: selectarea corectă a terenurilor potrivite pentru plantarea lui; posedarea unui sortiment cu capacităţi înalte de adaptare la varierea condiţilor pedo-climatice, tolerante, sau cu rezistenţă relativă la bolile principale, vigoare redusă (medie sau mică) a pomilor, formaţiuni fructifere scurte şi mijlocii, coroană compactă, diferite epoci de maturare a fructelor; productivitate mare şi în plus autocompatibilitate şi interfertilitate; calităţi superioare a fructelor. Astfel, sortimentul acualmente înregistrat pentru multiplicare industrială constă din 20 soiuri (10 introduse şi 10 create în cadrul IŞPHTA), în principal soiuri destul de bine adaptate la condiţiile edafice şi climatice locale. De notat că în sarcina modernizării sortimentului de cais actualmente un accent deosebit se pune pe ameliorarea, precum şi elaborarea (în baza diferitor secvenţe tehnologice) a calităţilor deosebite ale fructelor. Astfel, calităţile comerciale valoroase includ: mărime-de minimum $45 \mathrm{~g}$ /fruct; formă-rotundă, ovală şi fără adîncituri prea proeminente la sudura ventrală, la vîrful fructului, sau în cavitatea pedunculară; pieliţa subţire,cu pubescenţă fină, de culoare portocalie pînă la roşu, crem sau limonie; fermitate bună, structură şi culoare delicată a pulpei (alb, galben, portocaliu), sîmbure relativ mic (în condiţii de irigare de maximum 5\% ); coacere uniformă şi simultană. Calităţi nutritive, terapeutice şi biostimulatoare: arome plăcute, conţinut înalt de elememte nutritive ( substanţă uscată - mai mult de 20\%, zaharuri - 10-15\%, acizi organici - mai mult de 15, vitamina C-mai mult de $20 \mathrm{mg} / \%$, în abundenţă pectine, polifenoli, carotinoizi-drept componente antioxidante,calciu, caliu, microelementele de bază; pretabilitate la diferite forme de industrializare (inclusiv dehidratare). În linii mari în evaluarea şi modernizarea calităţii fructelor de cais trebuie să fie respectate criteriile: "sănătate", "savoare", "securitate" şi "serviciu". Studiul comparativ al multor soiuri introduse, preferate pe piiețele de vîrf al caiselor proaspete ne-au permis selectarea celor mai convenabile, atît din punctul de vedere productivității relativ stabile, al adaptabilității la condițiile pedoclimatice din țară, cît și al compatibilității perioadelor de înflorire cu cele locale, accent prioritar fiind pus de asemenea pe cele autofertile cu intrare rapidă pe rod economic (tab. 1). Astfel, cercetările experimentale multianuale efectuate în IŞPHTA, inclusiv hibridarea intravarietală, cultura de embrioni imaturi, studiul comparativ al particularităţilor biologice şi de producţie a genotipurilor locale și a celor introduse din diferite arealuri de cultivare a caisului au condus spre evaluarea şi testarea în producţie a peste 25 de soiuri introduse și selecţii locale de perspectivă, înregistrarea soiurilor locale Vasile Cociu și 
Codrean, selectarea unor elite de perspectivă pentru programele viitoare de ameliorare varietală a caisului pentru condiţiile locale (tab. 1, fig. 1,C , F). În tab.1 sunt generalizate caracteristicile de bază inovative ale soiurilor locale recent omologate, precum și a celor mai promițătoare pentru cultivare și utilizare în programe de ameliorare varietală pentru condițiile din Rep. Moldova.

Dintre soiurile locale, create în IȘPHTA, cele mai importante sunt Vasile Cociu și Codrean.

Soiul Vasile Cociu. Este obţinut la IŞPHTA de la încrucişarea soiurilor Stark Early Orange x Kostiujenskii. Pomul. Vigoarea: medie cu coroana oblong rotunjită. Intrarea pe rod: anii 3-4, producţia crescînd rapid de la an la an. Productivitatea: 14-20 t/ha. Înflorirea relativ tardivă. Polenizatori eficienţi: Krasnoşciokii, Moldavskii olimpieţ, Kostiujenskii, Stark Early Orange. Rezistenţa: comparativ rezistent la boli, şi foarte rezistent la geruri de iarnă. Zona de cultivare: înregistrat în Registrul soiurilor de plante de perspectivă pentru toate zonele de cultivare a caisului din Republica Moldova din anul 2013. Fructul. Mărimea: masa medie 48-80g, dependent de nivelul de aplicare a măsurilor agrotehnice standard. Forma: ovoidal-alungită cu vîrful punctat, cu sutura ventrală mediu proeminentă. Pieliţa: glabră, fină, elastică, portocalie, netedă cu roşu aprins pe mai mult de $80 \%$ din suprafaţă. Pulpa: fermă şi fină, galbenă-portocalie, suculentă, dulce-acidulată cu gust excelent la maturarea deplină. Sîmburele relativ mic, se detaşează uscat de la pulpă. Epoca recoltării: decada întîia a lunii iulie.

Tabelul 1

Caracteristicile de bază ale unor soiuri noi de cais

\begin{tabular}{|c|c|c|c|c|c|c|c|}
\hline SOIUL & $\begin{array}{c}\text { Vigo } \\
\text { a } \\
\text { rea }\end{array}$ & $\begin{array}{c}\text { Fertilitate } \\
\text { a }\end{array}$ & $\begin{array}{l}\text { Productivitate } \\
\quad \text { a }\end{array}$ & $\begin{array}{c}\text { Masa } \\
\text { medie a } \\
\text { fructelo } \\
\mathbf{r} \\
\end{array}$ & \begin{tabular}{|l|} 
Culoiare \\
a pulpei
\end{tabular} & \begin{tabular}{|c|c|c|c|} 
Destinaţi \\
a
\end{tabular} & $\begin{array}{l}\text { Caracteristici } \\
\text { importante }\end{array}$ \\
\hline \multicolumn{8}{|c|}{ Soiuri noi create în rep. Moldova } \\
\hline $\begin{array}{l}\text { Vasile } \\
\text { Cociu }\end{array}$ & ++ & $\begin{array}{l}\text { Parțial } \\
\text { Autofertil }\end{array}$ & +++ & +++ & $\begin{array}{c}\text { Gaben- } \\
\text { oranj }\end{array}$ & CP,PR & $\begin{array}{c}\text { Calitatea fructelor. } \\
\text { Productivitate. } \\
\text { Înflorire tardivă } \\
\text { Rezistență bună la } \\
\text { factorii nefavorabili } \\
\text { abiotici locali. }\end{array}$ \\
\hline Codrean & +++ & Autofertil & +++ & +++ & Galben & CP, PR & $\begin{array}{c}\text { Calitatea foarte bună a } \\
\text { fructelor la procesare. } \\
\text { Rezistenţă bună la } \\
\text { factorii nefavorabili } \\
\text { abiotici locali }\end{array}$ \\
\hline \multicolumn{8}{|c|}{$\begin{array}{c}\text { Soiuri noi inovative introduse /în ordinea perioadei de maturare a fructelor: începutul lunii iunie- } \\
\text { sfărlitul lunii august/ }\end{array}$} \\
\hline Tsunamy & +++ & Autofertil & +++ & +++ & $\begin{array}{c}\text { Gaben- } \\
\text { oranj }\end{array}$ & $\mathbf{C P}$ & \begin{tabular}{|c|} 
Timpurietatea \\
maturării, calitatea \\
fructelor Rezistență \\
bună la factorii \\
nefavorabili abiotici \\
locali
\end{tabular} \\
\hline $\begin{array}{c}\text { Wonder } \\
\text { Cot }\end{array}$ & ++ & Autosteril & ++ & ++ & $\begin{array}{l}\text { Gaben- } \\
\text { oranj }\end{array}$ & $\mathbf{C P}$ & $\begin{array}{c}\text { Timpurietatea } \\
\text { maturării, calitatea } \\
\text { fructelor Rezistență } \\
\text { bună la factorii }\end{array}$ \\
\hline
\end{tabular}




\begin{tabular}{|c|c|c|c|c|c||c|c|}
\hline $\begin{array}{c}\text { Spring } \\
\text { blush }\end{array}$ & ++ & Autosteril & +++ & ++ & Oranj & CP & $\begin{array}{c}\text { Timpurietatea } \\
\text { maturării, calități } \\
\text { remarcabile a } \\
\text { fructelor. }\end{array}$ \\
\hline $\begin{array}{c}\text { Orangere } \\
\text { d }\end{array}$ & ++ & Autofertil & +++ & ++ & $\begin{array}{c}\text { Gaben- } \\
\text { oranj }\end{array}$ & CP & $\begin{array}{c}\text { Timpurietatea } \\
\text { maturării, calitatea } \\
\text { fructelor. }\end{array}$ \\
\hline Pinkot & +++ & Autofertil & +++ & ++ & Oranj & CP & $\begin{array}{c}\text { Perioada lungă de } \\
\text { înflorire.Timpurietate } \\
\text { a relativă a maturării, } \\
\text { calitatea fructelor. } \\
\text { Necesită irigare }\end{array}$ \\
\hline Kyoto & +++ & Autofertil & +++ & ++ & $\begin{array}{c}\text { Gaben- } \\
\text { oranj }\end{array}$ & CP & $\begin{array}{c}\text { Calitatea fructelor. } \\
\text { Necesită irigare. }\end{array}$ \\
\hline Big red & +++ & Autosteril & +++ & ++ & Oranj & CP & $\begin{array}{c}\text { Rezistenţă bună la } \\
\text { factorii nefavorabili } \\
\text { abiotici locali calitatea } \\
\text { fructelor. Necesită } \\
\text { irigare }\end{array}$ \\
\hline Faralia & +++ & Autofertil & +++ & +++ & Oranj & CP & $\begin{array}{c}\text { Tardivitatea maturării } \\
\text { și fermitatea, calitativă } \\
\text { a fructelor }\end{array}$ \\
\hline Rubista & +++ & Autofertil & +++ & ++ & $\begin{array}{c}\text { Oranj } \\
\text { inchis }\end{array}$ & CP & $\begin{array}{c}\text { Uniformitatea } \\
\text { maturării, predomnnă } \\
\text { culoare roșie închisă a } \\
\text { pieliței fructeloir. } \\
\text { Aromă slabă. }\end{array}$ \\
\hline
\end{tabular}

Legendă: $+++=$ mare, $++=$ medie, + mică. $\mathrm{CP}=$ consum proaspăt, $\mathrm{PR}=$ procesare

Fructele sunt rezistente la manipulare şi transport. Utilizarea: pentru consum în stare proaspătă şi prelucrare industrială. Avantaje, efectul economic şi social preconizat. Soi de cais cu coacere timpuriu-medie a fructelor de calibru mare şi atractivitate înaltă, care completează conveierul de utilizare a fructelor proaspete de cais de calitate excelentă şi sezonul de prelucrare a fructelor acestei specii. Efectul economic constituie peste 4550 lei/ha. Este soi autorizat pentru răspîndire în Republica Moldova. Datorită calităţilor deosebite ale fructelor şi rezistenţei bune la factorul termic (atît gerurile de iarnă, cît şi seceta atmosferică din perioada de dezvoltare a fructelor) soiul poate fi cultivat in mai multe microarealuri agricole din cadrul zonelor, specificate pentru pomicultură în republica Moldova. Fiind recoltat la maturarea tehnică, poate fi transportat la distanţe lungi datorită fermităţii deosebite a fructelor. 


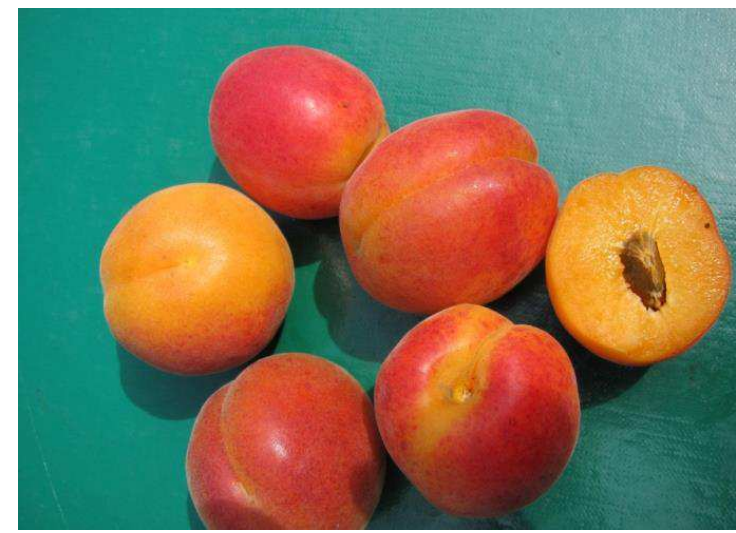

A

B
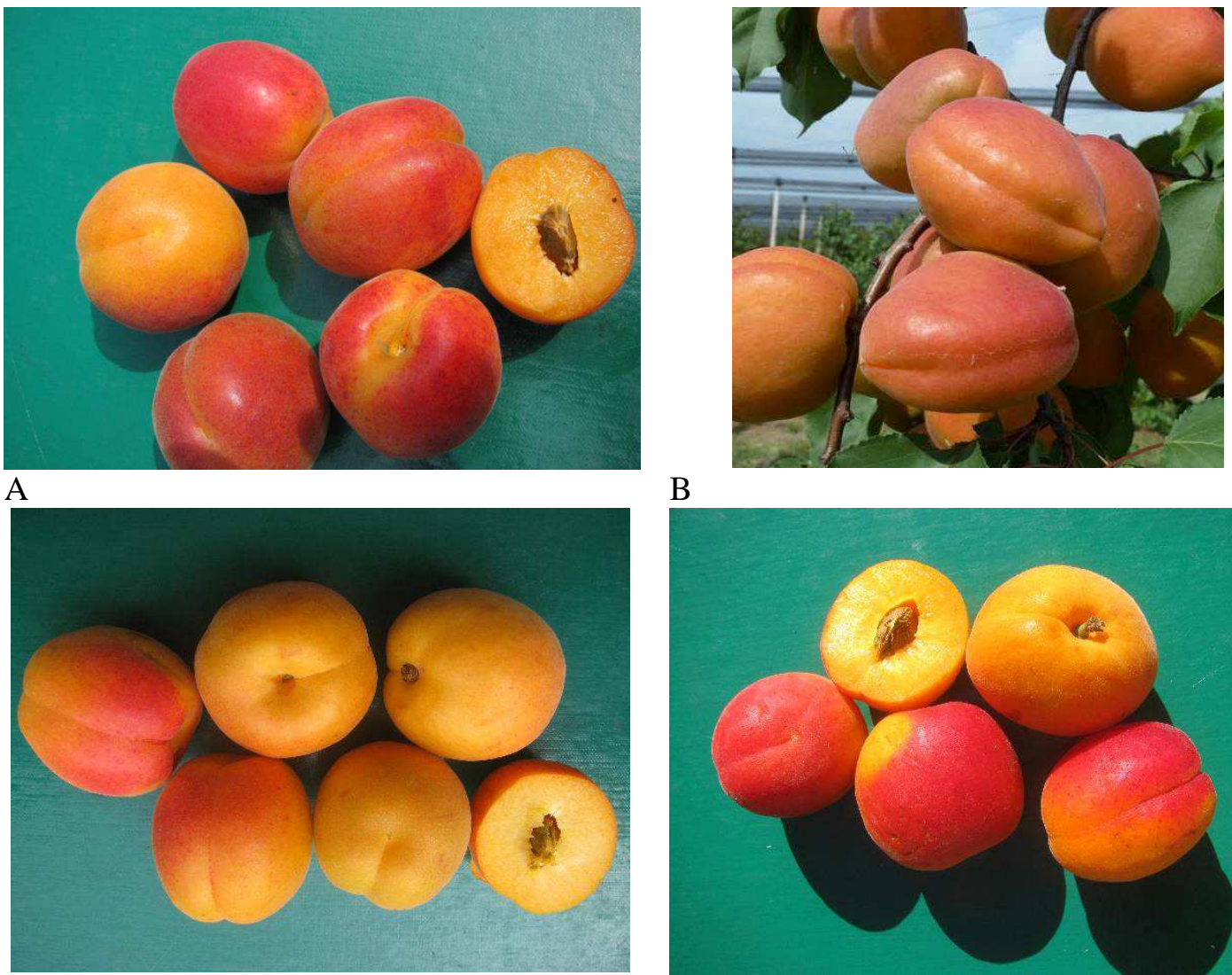

$\mathrm{C}$

$\mathrm{D}$
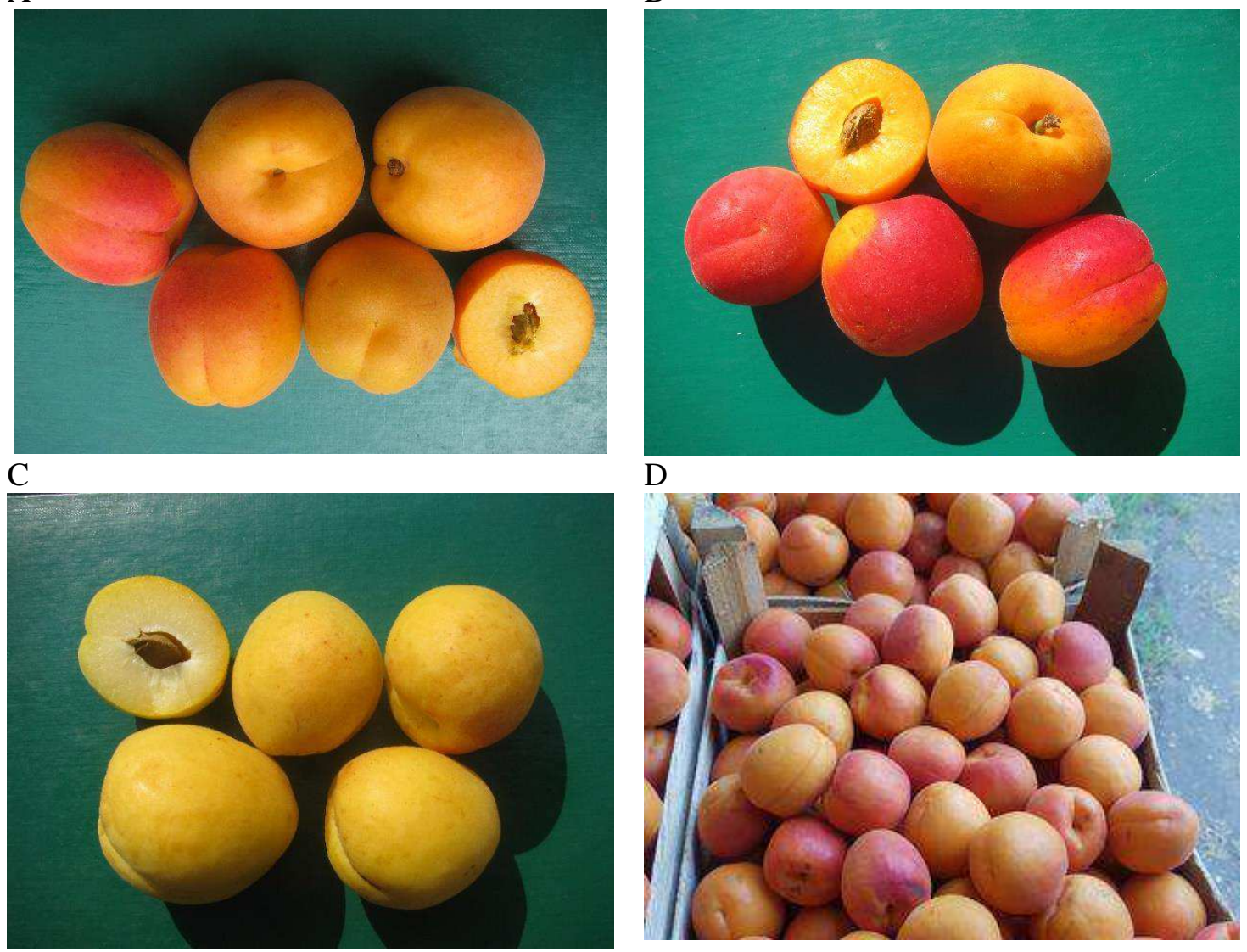

$\mathrm{F}$

Fig. 1.A-Orangered; B-Faralia, C-Kyoto, D-Pinkot, E-Codreran, F-Vasile Cociu la fermierii locali

Codrean. Este obținut prin polenizarea liberă a soiului Kişinevskii rannii cu aplicarea culturii de embrioni inâmaturi in vitro. Pomul de vigoare medie spre mare, cu coroana globuloasă de desime medie. Formaţiunile fructifere de bază sunt smicelele, ramurile mixte şi mai puţin buchetele de mai. Intră pe rod la anul 4 de la plantare şi produce relativ mult (25-35 kg/pom). Epoca de înflorire-medie, gradul-abundent. Polenizatori eficienţi: Krasnoşciokii, Kişinevskii rannii. Fructul. Calibru-mare: 50-60 gr. fără irigare, de formă rotundă cu vărful 
rotunjit, sutura ventrală slab pronunţată; pieliţa subţire, catifelat pubescent[, de culoare galben-închis. Pulpa de fermitate bună, destul de suculentă la maturarea deplină, ne aderentă la sîmbure, oranj deschis, gustul dulce slab acidulat. Fructele se caracterizează printr-un conţinut relativ înalt de substanţe organice. Sîmburele este mic (5,6-6,0\%). Maturarea fructelor are loc în decada a treia a lunii iunie, aproape de soiul Kişinevskii rannii. Nota de degustare a fructelor proaspete este de 4,50. Destinaţia - consum proaspăt şi pentru prelucrare industrială (suc, gem). Posedă rezistenţă medie la ger, secetă, boli criptogamice. Se recomandă a fi recoltat la maturarea tehnică pentru a-l putea păstra în condiții controlate şi transporta la comercializare timp de cîteva zile.

\section{Concluzii}

1. În baza cercetărilor experimentale și de încercare în producție a soiurilor locale Vasile Cociu şi Codrean, conveierul varietal s-a îmbogăţit şi diversificat în direcţia optimizării asigurării perioadei de consum a fructelor în stare proaspătă, pentru transportare la distanțe lungi şi prelucrare industrială.

2. După complexul de caracteristici biologice şi agronomice evaluate in baza datelor calităţilor specifice ale fructelor, producţiei mari de fructe precum şi datorită adaptabilităţii sporite către condițiile de mediu şi a plasticităţii ecologice largi, soiurile introguse Kioto, Farbaly, Pincot pot servi în calitate de donatori în programele de ameliorare a caisului pentru Rep. Moldova

\section{Bibliografie}

1. Catalogul soiurilor de plante al Republicii Moldova pentru anul 2020. Chişinău.2020. P. 64-65

2. Cociu V, Şt. Oprea. Metodele de cercetare în ameliorarea plantelor pomicole. ClujNapoca, 1989, 123p.

3. Isacova M. D., Smîcov V. K. Selecţia abricosa v SSR Moldova. //Sortoizucenie i selecţia plodovâh cultur. Kişinev, 1991, s. 37-53.

4.Lespinasse, Y. Review on pome fruit breeding in Europe. Which strategy for near future? //Acta Hortic.2009, 814, P865-872

5. Masiukova O.V., Bucarciuk V.F. Metodî issledovanii plodovîh rasteniipri izucenii $i$ vîvedenii sortov. Chişinău, 2005, 44s.

6. Pîntea M. Sortimentil de cais omologat şi de perspectivă. //Cercetări în Pomicultură . Vol. I.(Institutul de Cercetări pentru Pomicultură). Chişinău. 2002. P.59-65.

7. Pîntea M. Cultivarea caisului. Chişinău. 2003. 56 p. 